\title{
Structure of Copper Oxide Species Supported on
}

\section{Monoclinic Zirconia}

Vera P. Pakharukova, ${ }^{a, b} *$ Ella M. Moroz, ${ }^{a}$ Dmitry A. Zyuzin, ${ }^{a}$ Arcady. V. Ishchenko, ${ }^{a}$ Lidiya Yu. Dolgikh, ${ }^{c}$ Peter E. Strizhak ${ }^{c}$

a) Boreskov Institute of Catalysis, SB RAS, Pr. Lavrentieva 5, 630090 Novosibirsk, Russia

b) Novosibirsk State University, Pirogova Str. 2, 630090 Novosibirsk, Russia

c) Pisarzhevskii Institute of Physical Chemistry of the NAS, Pr. Nauki 31, 03039 Kiev, Ukraine

\section{S1.}

The X-ray photoelectron (XP) spectra were measured on an ES300 electron spectrometer (Kratos Analytical, United Kingdom). The $\mathrm{MgK} \alpha$ radiation $(\mathrm{E}=1253.6 \mathrm{eV})$ was used. The spectra were recorded at $13 \mathrm{kV} \times 5 \mathrm{~mA}$ (radiation power - $65 \mathrm{~W}$ ). To determine the electronic state of the surface elements, high resolution spectra of core photoelectron lines of individual elements were recorded with the energy step of $0.1 \mathrm{eV}$ at the analyzer pass energy of $25 \mathrm{eV}$. The spectra were calibrated with respect to the $\mathrm{C} 1 \mathrm{~s}$ line at $284.8 \mathrm{eV}$. Curve fitting analysis of the XP spectra was performed by Gaussian-Lorentzian components using XPS-Calc original software.

Figure $1 \mathrm{~S}$ shows $\mathrm{XP} \mathrm{Zr} 3 \mathrm{~d}$ core level spectra of the $\mathrm{m}-\mathrm{ZrO}_{2}$ and $10 \mathrm{Cu} / \mathrm{ZrO}_{2}$ catalyst. $\mathrm{XP} \mathrm{Zr} 3 \mathrm{~d}$ spectrum of the support exhibits one main doublet at a binding energy (BE) of $181.9 \mathrm{eV}$, which is indicative of zirconium (IV) oxide, ${ }^{1}$ and negligible additional doublet at lower BE of $180.1 \mathrm{eV}$. However, for $10 \mathrm{Cu} / \mathrm{ZrO}_{2}$ catalysts there is a peak broadening related to increase in intensity of 
doublet at $180.8 \mathrm{eV}$. The observed lower $\mathrm{BE}$ value is attributable to formation of surface zirconium sites having relatively higher electron density. Similar effect has been previously observed for $\mathrm{Cu} / \mathrm{t}-$ $\mathrm{ZrO}_{2}$ catalysts and was ascribed to interaction between zirconia surface and supported copper species. $^{2}$

The XP Cu2p spectrum of the $10 \mathrm{Cu} / \mathrm{ZrO}_{2}$ catalyst exhibit peaks at about $934.4 \mathrm{eV}$ accompanied by intense shakeup satellite peaks at $939-946 \mathrm{eV}$, which are characteristic for $\mathrm{Cu}^{2+}$ species. ${ }^{3}$ The peak at $932.9 \mathrm{eV}$ is characteristic for $\mathrm{Cu}^{0}$ and $\mathrm{Cu}_{2} \mathrm{O}$ species. ${ }^{3}$ Detection of significant amount of $\mathrm{Cu}^{0}$ or $\mathrm{Cu}^{+}$contradicts XANES and RDF data. Observation of the reduced copper species seems to result from photoreduction in the spectrometer, when $\mathrm{x}$-ray radiation under the high vacuum environment effects removing the labile oxygen species of highly dispersed copper (II) oxide species.
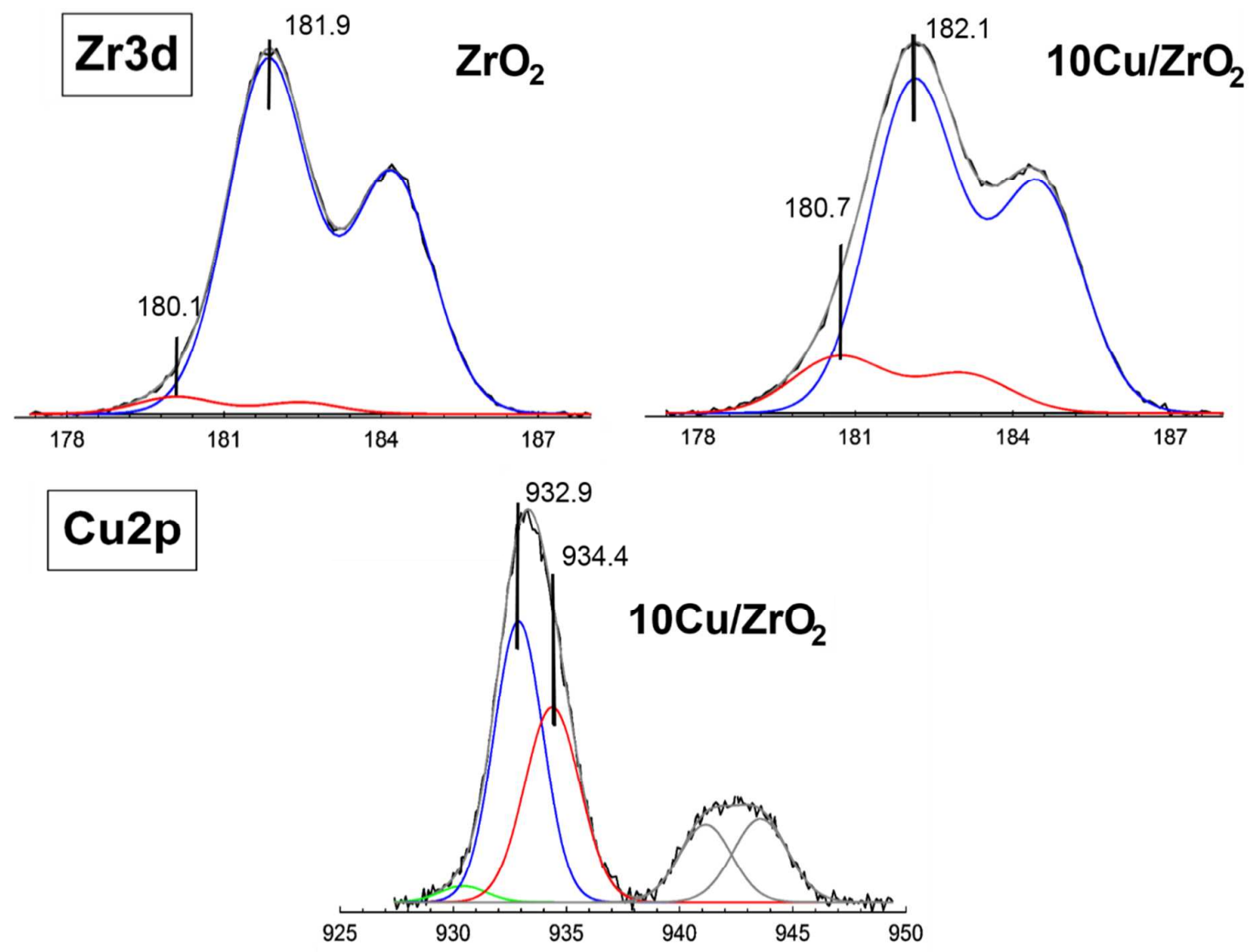

Figure S1. XP $\mathrm{Zr} 3 \mathrm{~d}$ spectra of the $\mathrm{m}-\mathrm{ZrO} \mathrm{r}_{2}$ support and $10 \mathrm{Cu} / \mathrm{ZrO}_{2}$ catalyst; $\mathrm{XP} \mathrm{Cu} 2 \mathrm{p}$ spectrum of the $10 \mathrm{Cu} / \mathrm{ZrO}_{2}$ catalyst. 
S2.

Distinguishing between size and strain $(\Delta \mathrm{d} / \mathrm{d})$ contributions to the line broadening was performed for $\mathrm{CuO}$ phase by means of Williamson-Hall plots. The Williamson-Hall plots are displayed in Fig.

S2.

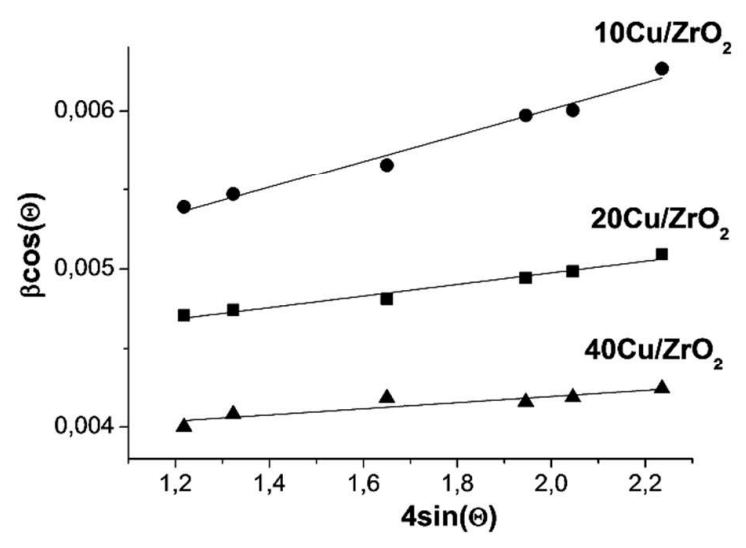

Fig. S2. Williamson-Hall plots used for distinguishing between size and strain contributions to broadening of the diffraction peaks attributable to the $\mathrm{CuO}$ phase in the $\mathrm{Cu} / \mathrm{ZrO}_{2}$ catalysts. 
S3.

XANES spectra of the Cu-K edge were obtained at the EXAFS Station of SSTRC. The storage ring VEPP-3 with the electron beam energy of $2 \mathrm{GeV}$ and the average current of $90 \mathrm{~mA}$ was used as the source of radiation. The X-ray energy was monitored with a channel cut Si (111) monochromator. All the spectra were recorded under transmission mode using two ionization chambers as detectors with a step of $\sim 0.3 \mathrm{eV}$. The samples were prepared in the form of pellets to obtain the absorption jump at the $\mathrm{Cu}-\mathrm{K}$ edge $\sim 0.5$. The crystalline compounds $\mathrm{CuO}, \mathrm{Cu}_{2} \mathrm{O}$ and $\mathrm{Cu}^{0}$ foil were used as reference samples.

The $\mathrm{Cu}-\mathrm{K}$ edge spectra of the catalysts resemble that of the $\mathrm{CuO}$ oxide indicating the presence of $\mathrm{Cu}^{2+}$ species in the catalysts.

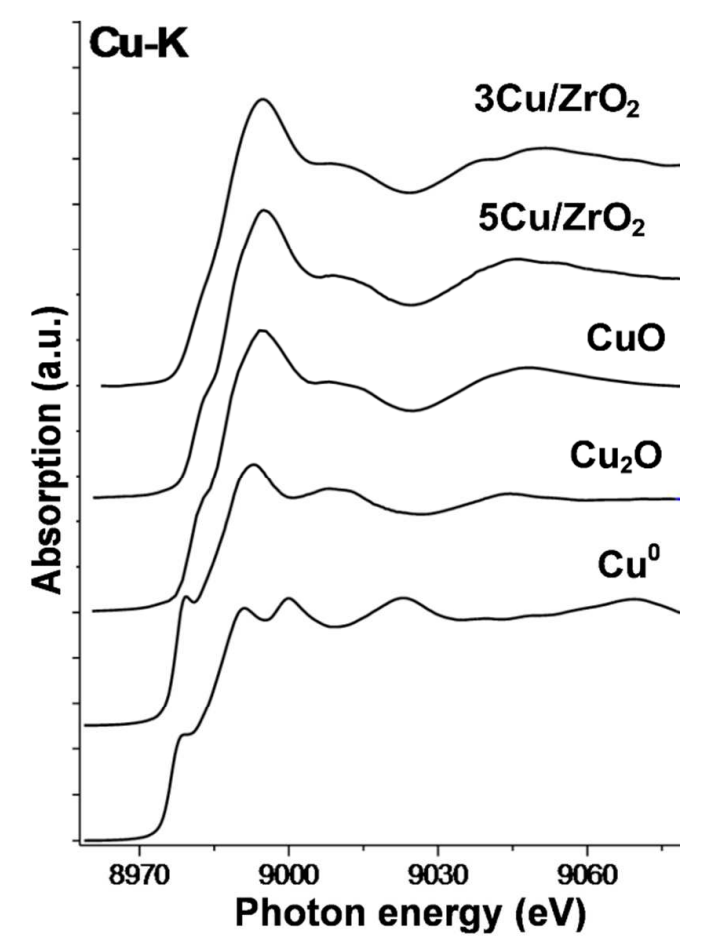

Fig. S3. XANES spectra $(\mathrm{Cu}-\mathrm{K}$ edge $)$ of the $\mathrm{Cu} / \mathrm{ZrO}_{2}$ catalysts and reference samples $\left(\mathrm{Cu}^{0}, \mathrm{Cu}_{2} \mathrm{O}\right.$, $\mathrm{CuO})$. 


\section{References}

(1) Ardizzone, S.; Bianchi, C. L. XPS Characterization of Sulphated Zirconia Catalysts: the Role of Iron Surf. Interface Anal. 2000, 30, 77-80.

(2) Pakharukova, V. P.; Moroz, E. M.; Kriventsov, V. V.; Larina T. V.; Boronin A. I.; Dolgikh, L. Yu.; Strizhak, P. E. Structure and State of Copper Oxide Species Supported on Yttria-Stabilized Zirconia. J. Phys. Chem. C. 2009, 113, 21368-21375.

(3) Ghijsen, J.; Tjeng, L. H.; van Elp, J.; Eskes, H.; Westerink, J.; Sawatzky, G. A. Electronic Structure of $\mathrm{Cu}_{2} \mathrm{O}$ and $\mathrm{CuO}$ Phys. Rev. B 1988, 38, 11322-11330. 